\title{
West German clinical research seeks new directions
}

\section{Munich/Bonn}

REBUILDING medical research after the Second World War has been much more difficult than making the West German economy boom. Especially in clinical fields, West German medicine has not yet recaptured its reputation at the turn of the century. But the authorities are still trying.

The deficiency in clinical science has been a favourite theme of the Wissenschaftsrat, West Germany's science advisory council, for several years, but the federal government finally took heed in February, creating a programme to establish "clinical research groups" at university hospitals around the country.

The research ministry (BMFT) will spend as much as DM30 million per year in a five-year programme to establish up to 40 groups in a variety of clinical disciplines. Groups will include both physicians and basic researchers, to be paid by the federal government for six to nine years, when the appropriate regional government (Land) will take over the costs.

But the initiative will not solve longterm problems, nor pull good researchers out of the air. Although the budget will add significantly to the DM50-DM70 million granted in support for clinical research by the Deutsche Forschungsgemeinschaft (DFG), neither sum is large.

The lack of a broader programme can be traced to the structure and history of the university hospital system. Eberhard Buchborn, director of Munich University's city-centre clinic, says that clinical research is not organized into clinical research units as in Britain and the United States. The director of a clinic is responsible for patient care as well as research, and can divide up resources as he or she sees fit. But many physicians are not available for research because of teaching duties. Buchborn said the student/faculty ratio can be as high as $25: 1$, compared with $1: 1$ in the United States.

As clinic heads are also entitled to share in the clinic's profits from private patients, there seems also to be little incentive to spend them on basic research. As one biologist put it, "Why should a director put the profits into research when he can put it into his villa?" The salary of university clinic directors is between DM100,000 and DM150,000, but may be augmented by up to DM1 million a year, especially at clinics providing lucrative services such as radiology or surgery.

Buchborn nevertheless disputes the charge that clinic directors deliberately skimp on research spending. He says that, to become a clinic director, a physician must have done many years of research, which is the primary concern of the faculty that chooses the director. One check in the system is that a professor may not become head of the clinic awarding a postdoctoral qualification (Habilitation).

Among other reasons for the state of clinical research is that noted in a 1986 study by the Wissenschaftsrat, which found that 40 per cent of medical professors were forced to leave their posts in 1933, when the Nazis came to power. The study found that efforts to rebuild the West German health system were understandably concentrated on patient care, to the neglect of research. Buchborn adds that the university reforms of the 1970 s, which led to the splitting of many previous

clinics, made it difficult to create a critical mass of researchers.

Even so, there is hope that good will emerge from the government initiative. Several West German research groups have international reputations (Hannover in liver transplantation, ultrasound to destroy kidney and gall-bladder stones in Munich, for example), showing that obstacles can be overcome.

Unfortunately, the results of the programme are not expected to be uniform across West Germany. Even the three "model" groups, in Münster, Würzburg and Giessen, on which the programme was based, did not get approved without a fight after the trial period ended. The DFG, which is administering the programme, expects a struggle, especially in the northern Länder, in winning support after federal funding runs out.

Steven Dickman

\section{India becoming more attractive to companies and graduates}

\section{New Delhi}

THE 'brain drain' of qualified scientists from India is in decline, according to Ministry of Education estimates. The number of science and engineering graduates leaving the country annually is now less than 1,000 , or 2 per cent of the annual output. Only 10 per cent of graduates from the Indian Institutes of

$$
\begin{aligned}
& \text { The bad news is, they're } \\
& \text { all Sikh militants... }
\end{aligned}
$$

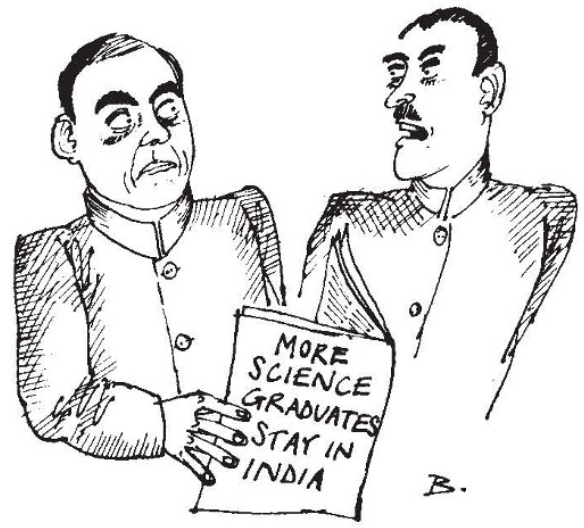

Technology migrated last year, compared with 20 per cent four years ago and nearly 40 per cent in 1977.

Factors behind this partial plugging of the brain drain are said to include increased opportunities for selfemployment, improved working conditions and higher salaries. And the Department of Science and Technology says that the newly created agencies in high-technology areas such as microelectronics, computers and biotechnology have created job opportunities for fresh grad- uates who might otherwise have migrated.

For one group of graduates, however, the government has decided to take more stringent action. Too many medical graduates have been leaving the country, so doctors "belonging to scarce categories" will not be allowed to emigrate, and medical graduates will be allowed to go abroad for training only if no suitable facilities are available. The Health Ministry is now helping new medical graduates to set up clinics in villages by arranging low-interest bank loans.

Fully owned subsidiaries of overseas high-technology companies are also helping to provide opportunities for Indian graduates staying at home. Comparatively low salary rates, together with the availability of qualified graduates, are attracting pharmaceutical and computer companies in particular.

Halting the loss of home-grown talent is one thing, but can the brain drain be reversed? The government now has several schemes under which Indian technologists get preferential treatment if they return to set up new enterprises in India. So far, the TOKTEN programme (for Transfer of Knowhow Through Expatriate Nationals) has successfully brought 170 expatriates to India for brief stays to work on specific projects.

The manpower division of the Council of Scientific and Industrial Research maintains a register of Indians wishing to return home. In the past 30 years, 24,000 Indians educated abroad have found jobs through this register. New registrants are being added to the list at a rate of about 40 per year, and the government hopes that the number will increase.

K. S. Jayaraman 